\title{
Sarcoidosis and lymphoma in the same patient
}

\author{
NEIL J. BRENNAN \\ M.B., M.R.C.P.I. \\ ROBERT P. TOWERS \\ M.D., F.R.C.P.I., F.R.C.(Path.)
}

\author{
JAMES J. FENNELLY \\ M.D., F.R.C.P.I. \\ MUIRIS X. FITZGERALD \\ M.D., F.R.C.P., F.R.C.P.I.
}

Department of Medicine, St Vincent's Hospital, Dublin 4

\begin{abstract}
Summary
A case of lymphocytic lymphoma in a patient with coincidental sarcoidosis is described, and the possible relationship of the two conditions is discussed. A revised set of diagnostic criteria is proposed to overcome previous difficulties encountered in validating such dual pathology.
\end{abstract}

KEY WORDS: sarcoidosis, lymphoma, hypogammaglobulinaemia.

\section{Introduction}

The coincidental occurrence of Hodgkin's disease and sarcoidosis is very uncommon. Rarer still are descriptions of non-Hodgkin's lymphoma and sarcoidosis in the same patient. We report a case of systemic sarcoidosis, confirmed histologically, where a well-differentiated lymphocytic lymphoma subsequently developed. We review the difficulties in validating such dual pathology and propose revised criteria for the acceptance of such cases. Furthermore, we discuss recent controversies concerning the nature of the relationship, if any, between sarcoidosis and lymphomatous disorders.

\section{Case report}

A 52-year-old nurse presented in August 1978 with dyspnoea and chest pain. Physical examination revealed splenomegaly and inguinal lymphadenopathy. Chest X-ray showed bilateral hilar adenopathy with diffuse pulmonary infiltrates. Investigations revealed the following abnormalities: forced vital capacity (FCV) 2.8 litres (90\% predicted); forced expiratory volume in 1 min $\left(\mathrm{FEV}_{1}\right) \mathrm{l} .95$ litres $(71 \%$ predicted); single breath diffusing capacity (transfer factor) $65 \%$ predicted: urinary calcium excretion 559 $\mathrm{mg} / 24 \mathrm{hr}$; serum immunoglobulins IgG $520 \mathrm{mg} / \mathrm{dl}$, IgA $80 \mathrm{mg} / \mathrm{dl}$, IgM $67 \mathrm{mg} / \mathrm{dl}$. The erythrocyte sedimentation rate was $9 \mathrm{~mm} / \mathrm{hr}$; other biochemical and haematological investigations proved normal. Histological examination of tissue obtained at mediastinoscopy revealed fragments of lymph-node which were extensively replaced by well-demarcated epithelioid cell and giant cell granulomata, without caseation, which were confluent in a few areas (Fig. 1). No micro-organisms were demonstrated and the appearances were regarded as highly consistent with sarcoidosis. On the basis of typical clinical, radiological, physiological, biochemical and histological features, the diagnosis of sarcoidosis was made. Treatment with $40 \mathrm{mg}$ of prednisone on alternate days was instituted with a prompt and complete resolution of all clinical and radiological abnormalities.

The patient went to the United States where the prednisone was slowly reduced to zero without recurrence of lymphadenopathy or pulmonary infiltrates. In February 1980, 20 months after the diagnosis of sarcoidosis, she was found on routine review to have marked splenomegaly and inguinal lymphadenopathy. Her chest X-ray remained normal. An inguinal lymph node biopsy and bone marrow biopsy was carried out. These have been reviewed by us and revealed obliteration of the normal architecture of the lymph-node with replacement by a uniform sheet of round cells with small nuclei and rather indistinct cell boundaries, the appearances being those of a diffuse malignant lymphoma of well-differentiated type (Fig. 2). The bone-marrow showed somewhat hypercellular haemopoietic marrow with extensive replacement by diffuse malignant lymphoma similar to that in the node. No granulomata were seen on any of the sections of lymphoma tissue.

She was treated with prednisone, $30 \mathrm{mg}$ daily, with partial reduction in the size of her spleen and lymph nodes. Subsequent relapse required treatment with combination chemotherapy but a further lymph node and liver biopsy in December 1980 both confirmed 


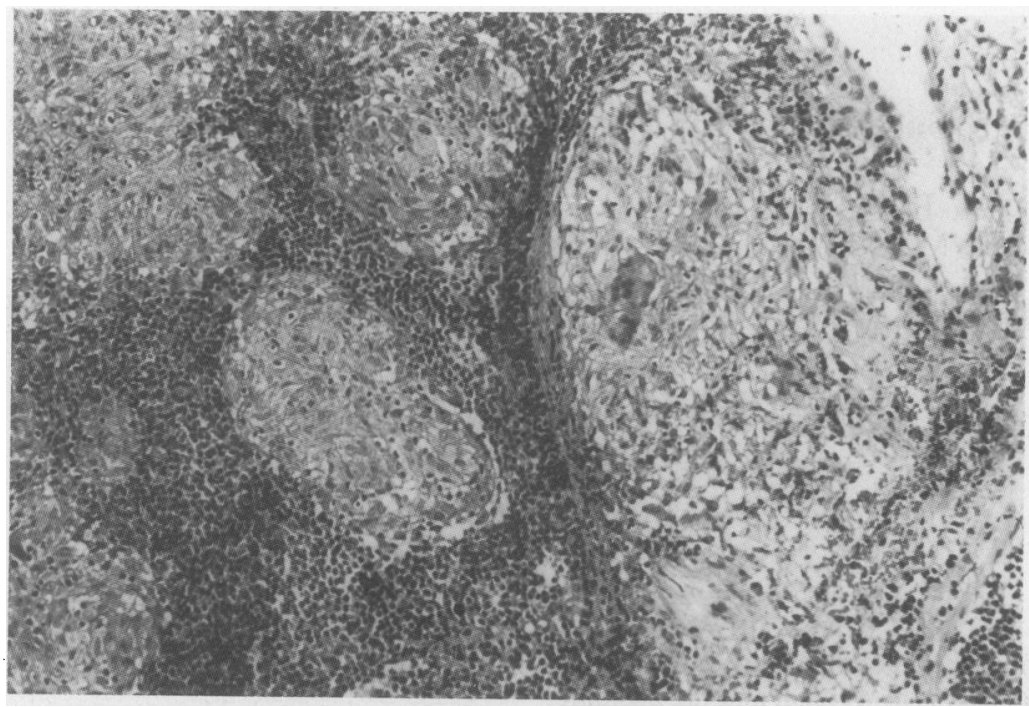

FIG. 1. Section of lymph-node showing sarcoid gramulomas. H.E., $\times 60$.

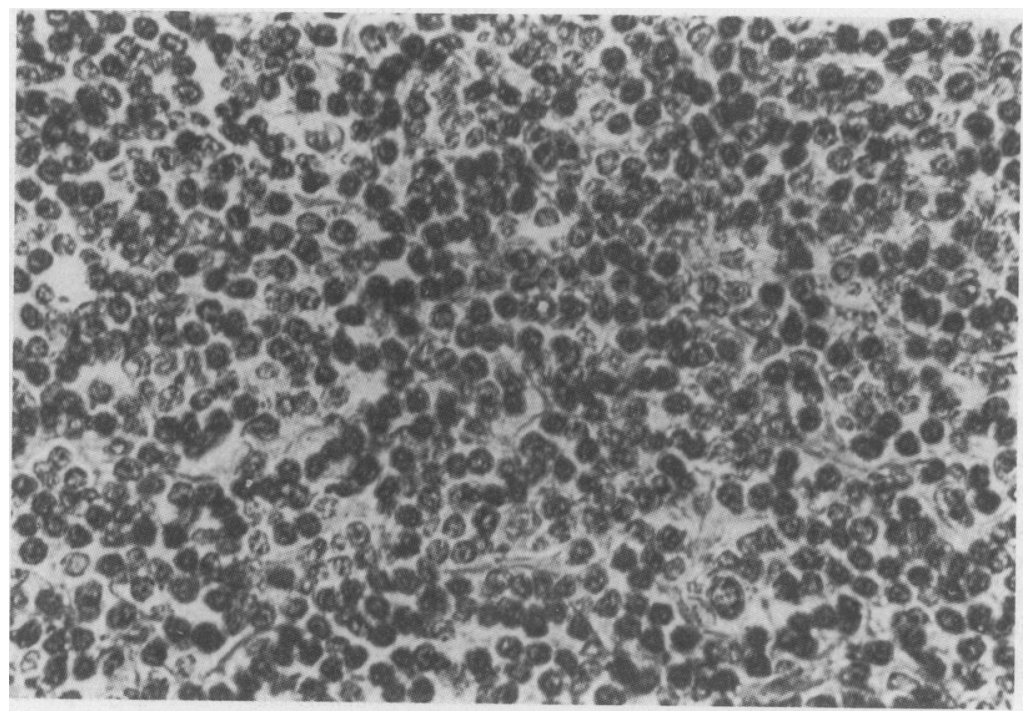

FIG. 2. High-power view of lymph-node showing well-differentiated lymphocytic lymphoma. H.E., $\times 240$.

the presence of lymphoma. No stigmata of sarcoidosis could be detected in any of these additional biopsies. In view of the persistent disease, she received 2,500 rads to the paraortic and inguinal areas with a good response. The patient is living in the United States at the time of writing.

\section{Discussion}

This case of sarcoidosis with a coincidental lymphoma prompts discussion under 3 headings: firstly, a review of the difficulties in confirming both diagnoses in the same patient; secondly, suggested. stricter criteria for the validation of such duab diagnoses; thirdly, a review of the nature of the relationship, if any, between the 2 disorders.

Diagnosis of sarcoidosis and lymphoma in the same patient may prove difficult to establish because the granulomatous lesion of sarcoid lacks specificity Sarcoid-like granulomas have been reported in infec⿱宀 tious diseases, following exposure to chemical agents in a variety of chronic inflammatory conditions and 


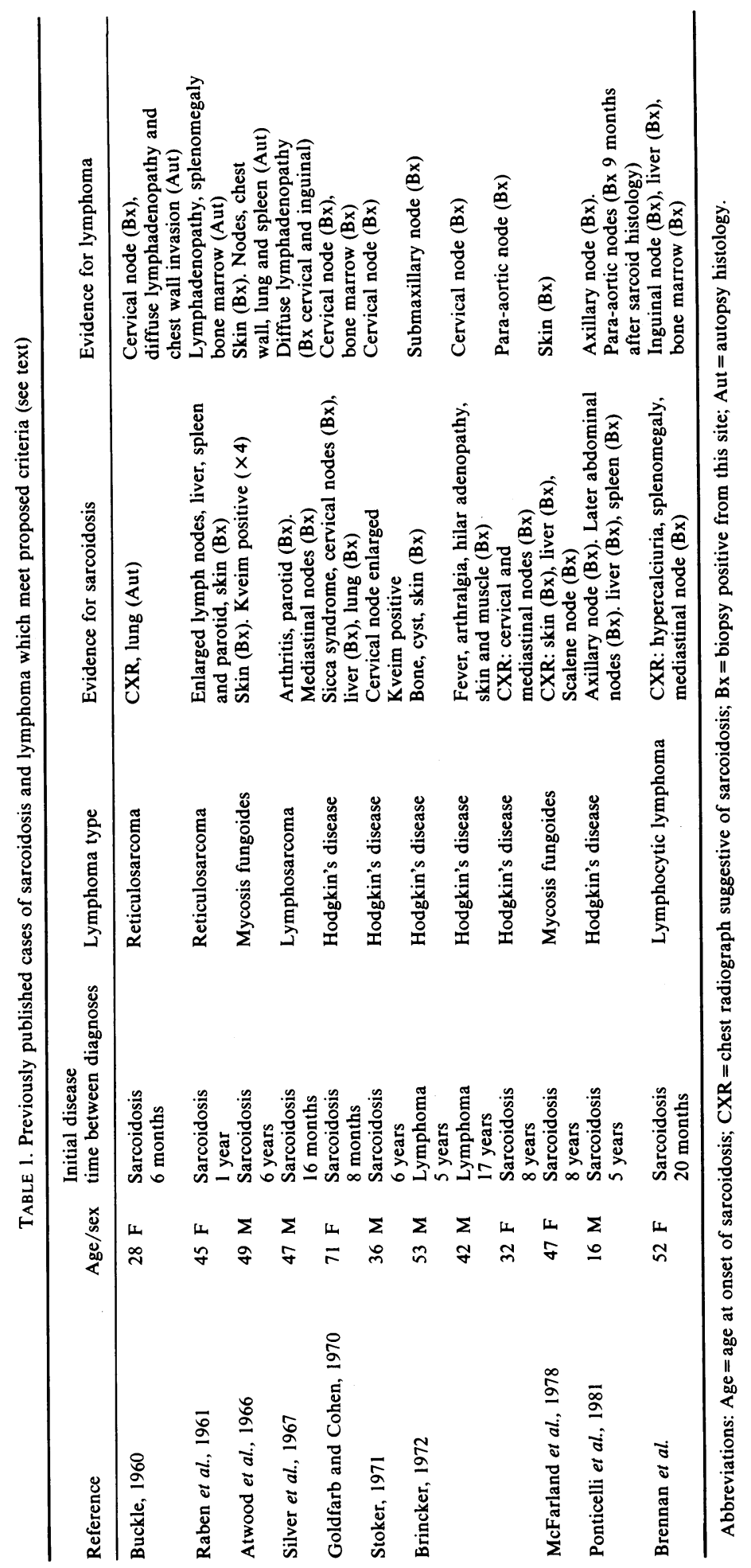


in lymph nodes draining an area containing a carcinoma (Anderson, 1943; Freiman, 1948; Gregorie, Otherson and Moore, 1962; Cohen et al., 1977). It is accepted that such changes do not represent true sarcoidosis. A further confounding factor is that scattered sarcoid-like granulomas are sometimes admixed with typical histological features of lymphoreticular neoplasms, particularly Hodgkin's disease, where they are found in 12-29\% of cases (Kadin, Donaldson and Dorfman, 1970; Neiman, 1977; Whittaker et al., 1978; Pick et al., 1978).

A diagnostic problem is clearly seen on reviewing previous case reports which purport to show coincidental sarcoidosis and lymphoma. In a recent review of the literature, Ponticelli, Arganini and Cionini (1981) accept 14 such cases although previous authors (Atwood, Miller and Nelson, 1966) had seriously questioned the acceptability of 2 of his cited cases (Rottino and Hoffman, 1950; Lamache et al., 1954). Indeed, we would question the criteria on which 3 further published cases (Foon, Filderman and Gale, 1981; Razis, Diamond and Craver, 1969) are based. These difficulties in diagnosis result from confusion between isolated granulomatous tissue reactions and true multisystem sarcoidosis, as defined by the 7 th International Conference on Sarcoidosis (1976).

We therefore suggest the following strict criteria for the acceptability of such cases of dual pathology. Firstly, each diagnosis should be separately and independently confirmed by biopsies from unrelated anatomical sites. Secondly, appropriate clinical, radiographic and biochemical features of each disease should be present; in particular, sarcoidosis should demonstrate multi-system involvement. Obviously, the longer the time interval between making the 2 diagnoses, the greater the probability that 2 separate disease processes are present. Finally, a previous additional stipulation (Silver, Nachnani and Breslow, 1967) that the sarcoidosis should remit or remain stable while the neoplastic lesion progresses seems an unrealistic criterion, since the natural history of sarcoidosis may be progressive in many cases.

Applying these criteria to previously published cases, we found 11 acceptable descriptions of coincidental sarcoidosis and lymphoma (Table 1). The chief points of interest are the predominance of Hodgkin's disease in the lymphoma group, the fact that sarcoidosis antedated lymphoma in the majority of cases, and the relatively late age of onset of sarcoidosis.

To date, the nature of the relationship between sarcoidosis and lymphoma remains unclear. Epidemiological studies have been carried out in an attempt to define whether there was an increased risk of malignant disease in patients with sarcoidosis (Brincker, 1972; Brincker and Wilbeck, 1974). They found that malignant lymphoma and lung cancer occurred respectively 11 and 3 times more frequent $B$ than expected. However, these data have recently been critically re-examined by Rømer (1980) an revised results failed to show any excess of tumour occurrence over that expected in the general population. On-going studies by $\mathrm{R} ø$ mer have so far failed reveal any evidence of an increased risk of malig nancy (Rømer, 1982). Obviously, further indepeR dent epidemiological studies in other populations ate needed.

Pathogenetically, shared features of sarcoidosis and lymphoma include the occurrence of granul $\overrightarrow{0}$ mata on histology, and the occurrence of cellular ang humoral immunological dysfunction in both di orders. In sarcoidosis, abnormal $T$ cell functio (James, Neville and Walker, 1975; Goodwin et afo 1979; Daniele, Dauber and Rossman, 1980) and tie resultant impairment in delayed hypersensitivity (Israel and Sones, 1965; Sharma and Beresford, 197\$ might predispose to malignancy (Brincker and Witbeck, 1974). The role of humoral mechanisms raised in our case by the finding of low serum immunoglobulins. Lymphoma risk is known to be increased in patients with congenital immuno-defict ency (Kersey, Spector and Good, 1973), auto-inmune disease (Tabal, Sokoloff and Barth, 1960; Lewis et al., 1975; Louie and Schwartz, 1979) and in those receiving immunosuppressant therapy (Hoove and Fraumeni, 1973). The observation that phoma occasionally precedes sarcoidosis (Brinckef, 1972) and recent descriptions of sarcoidosis followir immunosuppressive therapy of a variety of tumouss (Sybert and Butler, 1978; Trump et al., 1981) ha prompted the suggestion that sarcoidosis may repre sent a form of opportunistic infection (Israel, 1978). remains possible that an, as yet, unidentified cong mon immune abnormality or extrinsic factor, such as a virus, may predispose to both conditions.

Clearly, prospective epidemiological studies in variety of populations are needed to ascertam whether or not sarcoidosis is associated with lymph. reticular and/or other malignancies. Careful docu mentation of clinical cases using strict diagnostis criteria will complement such epidemiological stu ies and may provide a clue to the nature of the relationship.

\section{Acknowledgment}

Our thanks are due to Dr W. E. Finkelstein, St Joseph's Hospitah

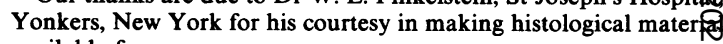
available for us.

\section{References}

ANDERSON, W.M. (1943) Bronchial adenoma with metastasis to the liver. Journal of Thoracic Surgery, 12, 351. 
Atwood, W.G., Miller, R.C. \& Nelson, C.T. (1966) Sarcoidosis and the malignant lymphoreticular diseases. Archives of Dermato$\log y, 94,144$.

BRINCKER, H. (1972) Sarcoid reaction and sarcoidosis in Hodgkin's disease and other malignant lymphomata. British Journal of Cancer, 26, 120.

BRINCKER, H. \& WILBEK, E. (1974) The incidence of malignant tumours in patients with respiratory sarcoidosis. British Journal of Cancer, 29, 247.

BUCKLE, R.M. (1960) Reticulosarcoma complicating sarcoidosis. Tubercle (London), 4I, 213.

Cohen, S.H., Fink, J.N., Garancis, J.C., Hensley, G.T., BarboRIAK, J.J. \& SCHLUETER, D.P. (1977) Sarcoidosis in hypersensitivity pneumonitis. Chest, 72, 588.

DANIELE, R.P., DAUBER, J.H. \& RosSMAN, M.D. (1980) Immunologic abnormalities in sarcoidosis. Annnals of Internal Medicine, 92, 406 .

Foon, K.A., Filderman, A. \& Gale, R.P. (1981) Histiocytic lymphoma following resolution of sarcoidosis. Medical and Pediatric Oncology, 9, 325.

Freiman, D.G. (1948) Sarcoidosis. New England Journal of Medicine, 239, 664.

GoldFARB, B.L. \& CoHEN, S.C. (1970) Coexistent disseminated sarcoidosis and Hodgkin's disease. Journal of the American Medical Association, 211, 1625.

Goodwin, J.S., Derhoratius, R., Israel, H., Peake, G.T. \& MESSNER, R.P. (1979) Suppressor cell function in sarcoidosis. Annals of Internal Medicine, 90, 169.

GREGORIE, H.B. Jr, OTHERSON, H.B. Jr \& MOORE, M.P. Jr (1962) The significance of sarcoid-like lesions in association with malignant neoplasms. American Journal of Surgery, 104, 577.

HOOVER, R. \& FRAUMENI, J.F. Jr (1973) Risk of cancer in renaltransplant recipients. Lancet, ii, 55.

ISRAEL, H.L. (1978) Sarcoidosis, malignancy and immunosuppressive therapy. Archives of Internal Medicine, 138, 907.

ISRAEL, H.L. \& SONES, M. (1965) Immunologic defects in patients recovered from sarcoidosis. New England Journal of Medicine, 273, 1003.

James, D.G., Neville, E. \& Walker, E. (1975) Immunology of sarcoidosis. American Journal of Medicine, 59, 388.

KADIN, M.E., DonaldSON, S.S. \& DoRFMAN, R.F. (1970) Isolated granulomas in Hodgkin's disease. New England Journal of Medicine, 283, 859.

KerSEY, J.H., SPECTOR, B.D. \& GoOD, R.A. (1973) Primary immunodeficiency diseases and cancer: the immunodeficiency registry. International Journal of Cancer, 12, 333.

LAMACHe, A., Chevrel, M.L., Bourel, M. \& RiChier, J.L. (1954) Poussee maligne mortelle (apres traitement cortisonique) au cours d'une reticulose a type de sarcoidose. Bulletin et Memoires de la Societe Médicale des Hôpitaux de Paris, 70, 1070.

LEWIS, R.B., CASTRO, C.W., KNISLEy, R.E. \& Bole, G.G. (1975) Frequency of neoplasia in systemic lupus erythematosis and rheumatoid arthritis. Arthritis and Rheumatism, 19, 1256.

LOUIE, S. \& SCHWARTZ, R.S. (1979) Immunodeficiency and the pathogenesis of lymphoma and leukaemia. Seminars in Haemato$\log y, 15,117$.

MCFARLAND, J.P., KAUH, Y.C. \& LUSCOMBE, H.A. (1978) Sarcoido- sis associated with mycosis fungoides. Archives of Dermatology, $114,912$.

NEIMAN, R.S. (1977) Incidence and importance of splenic sarcoidlike granulomas. Archives of Pathology and Laboratory Medicine, 101, 518.

Pick, A.I., Duer, D., Kessler, H., Zenan, Z., Weiss, H. \& TOPILSKI, M. (1978) Delayed hypersensitivity and lymphocyte transformation in patients with Hodgkin's disease and granulomas. Cancer, 41, 2192.

Ponticelli, P., ARganini, L. \& Cionini, L. (1981) Hodgkin's disease associated with sarcoidosis: Case report. Tumori, 67, 45.

Raben, A.C., Bogdanovich, N.K. \& Golochevskaya, V.S. (1961) A case of transformation of sarcoidosis into reticulosarcomatosis. Problems in Hematology and Blood Transfusion, 6, 763.

RaZIS, D.V., Diamond, H.D. \& CRAVER, L.F. (1969) Hodgkin's disease associated with other malignant tumours and certain nonneoplastic diseases. American Journal of the Medical Sciences, 238, 327.

RøMeR, F.K. (1980) Sarcoidosis and Cancer-a critical view. In: (Eds. W. Jones Williams and B.H. Davies) 8th International Conference on Sarcoidosis and other granulomatous diseases, $p$. 201. Alpha Omega Publishing, Cardiff.

RøMer, F.K. (1982) Case 7-1982, Sarcoidosis and Cancer (letter). New England Journal of Medicine, 306, 1490.

RotTino, A. \& HofFMAN, G. (1950).A sarcoid form of encephalitis in a patient with Hodgkin's disease; case report with review of the literature. Journal of Neuropathology and Experimental Neurology, 9, 103.

SEVENTH INTERNATIONAL CONFERENCE ON SARCOIDOSIS AND OTHER GRANULOMATOUS DISORDERS (1976) Annals of the New York Academy of Science, 278, 1.

SHARMA, O.P. \& BERESFORD, O.S. (1971) Immunological studies in patients recovered from sarcoidosis and tuberculosis. Indian Journal of Tuberculosis, 8, 84.

Silver, H.M., NAChNANI, G. \& BReslow, A. (1967) Lymphosarcoma and sarcoidosis. American Review of Respiratory Disease, 96, 290.

STOKER, T.A.M. (1971) Hodgkin's disease with sarcoid features. Proceedings of the Royal Society of Medicine, 64, 661.

SYBERT, A. \& BUTLER, T.P. (1978) Sarcoidosis following adjuvant high-dose methotroxate therapy for osteosarcoma. Archives of Internal Medicine, 138, 488.

TABAL, N., SoKoloff, L. \& BARTH, W.F. (1967) Extrasalivary lymphoid abnormalities in Sjogren's syndrome (reticulum cell sarcoma, pseudolymphoma macroglobulinaemia). American Journal of Medicine, 43, 50.

Trump, D.L., EtTinger, D.S., Feldman, M.J. \& Dragon, L.H. (1981) Sarcoidosis and sarcoid-like lesions-their occurrence after cytotoxic and radiation therapy of testis cancer. Archives of Internal Medicine, 141, 37.

Whittaker, J.A., Slater, A., Al-Ishail, S.A.D., Gough, J., Evans, K.T., Evans, I.H. \& Crosby, D.L. (1978) An assessment of laparotomy in the management of patients with Hodgkin's disease. Quarterly Journal of Medicine, 47, 291.

(Accepted 5 January 1983) 